\title{
Virtual diabetes consultations: meeting the IT governance challenge
}

\author{
HYMA RACHABATTULA, ${ }^{1}$ PAUL GRANT²
}

\begin{abstract}
Modern technologies are often underutilised in the traditional medical consultation. There are emergent areas of good practice where adoption of telemedicine applications has resulted in improved patient care and support for ongoing chronic disease self-management. Any new technology has to be as secure as possible in order to maintain confidentiality and the other tenets of good medical practice.

Br J Diabetes Vasc Dis 2015;15:112-113
\end{abstract}

Key words: telemedicine, diabetes, IT governance, patientcentred care, self-management

\section{Introduction}

The Diabetes Appointments via Webcam (DAWN) project in Newham, East London, led by Shanti Vijayaraghavan, is a testament to what can be achieved through imagination, innovation and good communication. ${ }^{1}$ DAWN has demonstrated that the use of open access video conferencing software and readily available computer and smartphone technology can support or even replace the traditional diabetes outpatient clinic meeting. Early results are encouraging, with a wide range of improvements in patient-related factors, such as convenience, acceptability, satisfaction, a reduction in non-attendance rates and visits to Accident and Emergency. Clearly, it is too early to evaluate hard clinical outcomes but early feedback is exciting at this time of transition as patients move to a new system. The process can certainly be of benefit to individuals with diabetes (or indeed any form of chronic disease which requires ongoing review) and clinicians.

"You are in the comfort of your own home. Sometimes in hospital I've felt the doctor was in control and you don't want to waste their time ... you feel liberated in your own home, it's on your terms"

\section{Information governance}

Remote consultations have been demonstrated to function well in several settings, with opportunities to realise significant

Department of Diabetes, Royal Sussex County Hospital, Eastern Road, Brighton.

2 Editor-in-Chief, BJDVD

Address for correspondence: Paul Grant E-mail: editorpg@bjdvd.com

http://dx.doi.org/10.15277/bjdvd.2015.031 benefits, but it is important to ensure that such patient interactions are secure and confidential and operated within a clear governance framework. Interestingly, the National Health Service has already made progress in this direction through the Quality, Innovation, Productivity and Prevention Digital Technology initiative: their guidance for online meetings which include patient identifiable data are fortunately sensible and robust. ${ }^{2}$

Many of the required local processes and controls to govern face to face meetings and consultations will already exist in organisations. Existing local clinical safety processes should continue to be used and discussion with the local Caldicott Guardian is important. Skype is perhaps the best known video conferencing software, which is freely available. However, some NHS trusts, including our own, deem this to be unsecure and recommend other similar programmes such as WebEx (www.webex.co.uk). The three key information governance (IG) areas that need to be considered when meeting online are:

1. Meeting preparation - to ensure that the meeting runs safely and is initiated by the clinician.

2. Issuance of a privacy statement - this will vary if the meeting is being recorded.

3. Safe storage and data protection - if an audio-visual recording is being made.

Figure 1 shows a summary diagram from the Cavendish Medical Practice (part of the Central London Clinical Commissioning Group) demonstrating how they have managed to incorporate IG into routine general practice. ${ }^{3}$

A sample checklist has also been developed for clinicians to use when conducting a telemedicine consultation:

- Informed patient consent must be obtained before the online consultation.

- The clinician must be in a private area where he/she cannot be overheard or their computer screen observed.

- Ensure that the patient's contact details are up to date and on their record. Only the details held on the record should be used to contact the patient.

- A consistent and robust local procedure must be in place to identify the patient.

- A privacy statement is read out to the patient at the beginning of the call.

\section{Conclusions}

Virtual diabetes consultations offer greater freedom and flexibility in relation to the traditional medical model.4,5 Individual providers, however, will need to make sure that safety and security are paramount to overcome any associated risks prior to going ahead with such an approach. 
Figure 1. Incorporating information governance (IG) into general practice: the Cavendish Medical Practice approach

\section{Cavendish Health Centre's process}

Before the clinic...

\begin{tabular}{c|c} 
Patient \\
contacts \\
practice
\end{tabular}$\longrightarrow \begin{gathered}\text { Receptionist } \\
\text { offers option } \\
\text { for Skype } \\
\text { consultation }\end{gathered} \longrightarrow$

Dear patient,

We note from your records that you have used the Skype pilot for a doctor's appointment at Cavendish Health Centre, or that you are interested in doing so.

As a user of this service, it is important that we make you aware that as with all information transmitted across the internet, the security of Skype isnt $100 \%$. If you have any concerns about this, you should use another isnt $100 \%$. If you have any concerns about this, you should

type of appointment. For more information, please visit:
https://support.skype.com/en/category/PRIVACY_SECURITY/

If you have any questions about this issue, please do not hesitate to contact Cavendish Health Centre. We hope you will continue to use

the Skype service for your appointments.

Many thanks

Cavendish Health Centre

Then, at the appointment time...

\begin{tabular}{|c|c|c|c|c|}
\hline $\begin{array}{l}\text { GP calls patient on Skype } \\
\text { - Patient calls are rejected } \\
\text { - Doctor can send messages } \\
\text { e.g. noting wait times }\end{array}$ & $\begin{array}{l}\text { IG reminders and } \\
\text { consultation } \\
\text { (if Skype unsuccessful, } \\
\text { doctor calls patient on } \\
\text { telephone) }\end{array}$ & $\begin{array}{l}\text { Clinical notes recorded } \\
\text { in SystmOne under } \\
\text { telemedicine } \\
\text { (event details) }\end{array}$ & $\begin{array}{l}\text { GP sends survey } \\
\text { link by Skype at } \\
\text { end of consultation }\end{array}$ & $\begin{array}{l}\text { GP completes audit data } \\
\text { Prescriptions can be } \\
\text { collected from practice, } \\
\text { or sent by post }\end{array}$ \\
\hline
\end{tabular}

\section{Acknowledgments Many thanks to Martin Gibson Conflict of interest None Funding None}

\section{References}

1. Vijayaraghavan S. Diabetes Appointments via Webcam in Newham (DAWN). http://connect.qualityincare.org/diabetes/initiative_supporting_a_positive_patient_experience_and_equality_of_care_in_hard_to_re ach_groups/case_studies/dawn_diabetes_appointments_via_webcam_in newham

2. Health and Social care Information Centre/QIPP Digital Technology. A brief guide to online meeting services. http://systems.hscic.gov.uk/qipp/library/onlinemtgfs.pdf (last accessed 14 May 2015).
3. Central London Clinical Commissioning Group/Cavendish Health Centre. Implementing Skype consultations in general practice. Update report on the Cavendish Health Centre Remote Consultation Service Pilot Project. December 2014. http://www.centrallondonccg.nhs.uk/media/24178/ CLCCG-Cavendish-Skype-pilot-interim-report.pdf (last accessed 12 May 2015).

4. Price C. Patients give thumbs up to GP Skype pilot. Pulse. Feb 2015. http://www.pulsetoday.co.uk/home/finance-and-practice-life-news/ patients-give-thumbs-up-to-gp-skype-pilot/20009161.article\#. VVXEX_CL1uo (last accessed 15 May 2015).

5. NHS England. NHSE using technology to beat cost of missed appointments. https://www.england.nhs.uk/2014/03/05/missed-appts/ (last accessed 15 May 2015). 